\title{
Use of peak expiratory flow for assessing bronchodilator responsiveness
}

\author{
*Ashutosh N Aggarwala, Ritesh Agarwala, Dheeraj Guptaa, Surinder K Jindala \\ a Department of Pulmonary Medicine, Postgraduate Institute of Medical Education and Research, Chandigarh, India
}

Received 29th February 2008; revised version received 12th June 2008; accepted 21st July 2008; online 15th October 2008

\begin{abstract}
Lung function in 1686 adult patients was measured before, and 15 minutes after, salbutamol inhalation. Bronchodilator responsiveness (BDR) was defined as a $12 \%$ improvement over baseline in either $\mathrm{FEV}_{1}$ or $\mathrm{FVC}$, along with an absolute volume increment of $200 \mathrm{ml}$. Peak expiratory flow (PEF) change, both absolute and relative to baseline, was also calculated ( $\triangle \mathrm{PEF}$ and $\triangle \mathrm{PEF} \%$, respectively). Change in $\mathrm{PEF}$ significantly correlated with change in $F E V_{1}$. However, $\triangle \mathrm{PEF}$ and $\triangle \mathrm{PEF} \%$ had poor discrimination in identifying BDR, with all specific cutoff values for $\triangle \mathrm{PEF}$ and $\triangle \mathrm{PEF} \%$ having low or moderate sensitivity, specificity and predictive values.

(C) 2009 General Practice Airways Group. All rights reserved.

AN Aggarwal et al. Prim Care Resp J 2009; 18(1): 50-52.

doi:10.3132/pcrj.2008.00064
\end{abstract}

Keywords lung function, assessment, bronchodilator responsiveness, spirometry, peak expiratory flow

\section{Introduction}

Spirometry is the recommended investigation both for diagnosis and categorisation of the severity of airflow limitation. ${ }^{1,2}$ Objective measurement of bronchodilator responsiveness (BDR) is useful in the clinical evaluation of these patients. The BDR test is carried out by performing baseline spirometric evaluation, with repeat spirometry after administration of a short-acting bronchodilator, and noting absolute and relative increments in observed vital capacity (VC) and/or forced expiratory volume in the first second $\left(\mathrm{FEV}_{1}\right)$.

However, spirometry is not widely available in primary care settings, and is often not performed routinely due to technical and logistic constraints. Peak expiratory flow (PEF) measurement is a simpler test in the assessment of obstructive airway disorders. The PEF instrument is cheap, portable and easy to operate and maintain. Guidelines on asthma suggest that either $\mathrm{FEV}_{1}$ or PEF can be used to categorise patients into various grades of disease severity and control.,3 Many clinicians also assume a general parity between these two measurements, although we have recently shown that this may not be correct. ${ }^{5}$

Nevertheless, it would be helpful if PEF could be used as a surrogate for spirometry in BDR assessment in primary care settings. A few investigators have studied this previously in both adults and children. ${ }^{6-9}$ However, these studies were conducted on small numbers of selected patients, and variable criteria were used to define BDR, making interpretation and comparison difficult. Some data suggest that, although lack of responsiveness in PEF can be used to exclude BDR, it is of much less value as a diagnostic test.,9

We therefore studied adult patients undergoing BDR testing to evaluate the performance of PEF measurement as an alternative to spirometry in diagnosing BDR.

\section{Patients and methods}

Records of all consecutive adult patients (aged more than 15 years) undergoing BDR testing during a six-year period (1999 to 2004) were retrieved and analysed retrospectively. Sources of referral, reasons for performing spirometry, and other clinical details were not analysed. All subjects had performed spirometry on a dry rolling seal spirometer (Spiroflow; P K Morgan Ltd.; Kent, U.K.) followed by PEF estimation using Wright's peak flow meter. VC, FEV 1 and PEF were measured by experienced technicians using American Thoracic Society guidelines..$^{10}$ The recorded PEF was corrected for the nonlinearity of the PEF meter using the equation: corrected PEF = 0.00075 PEF2 + 0.585 PEF + 53.2. This value was used for all subsequent analyses."

\footnotetext{
* Corresponding author: Dr Ashutosh N Aggarwal, Department of Pulmonary Medicine, Postgraduate Institute of Medical Education and Research,
} Sector 12, Chandigarh, 160012, India. Tel: +91 1722756824 Fax: +91 1722745959 E-mail: ashutosh@indiachest.org 
A diagnosis of BDR based on standard spirometric criteria was considered the gold standard. A patient was considered to have BDR if there was a $12 \%$ improvement over baseline in either $F E V_{1}$ or $F V C$, along with an absolute volume increment of $200 \mathrm{ml}, 15$ minutes after inhalation of 400 micrograms of salbutamol via a metered dose inhaler. ${ }^{1,2}$ The change in PEF, both absolute and relative to baseline, was also calculated ( $\triangle \mathrm{PEF}$ and $\triangle \mathrm{PEF} \%$ respectively). The correlation between change in pre-bronchodilator and postbronchodilator observations in PEF, and a corresponding change in $\mathrm{FEV}_{1}$ or $\mathrm{FVC}$ was studied. Overall discrimination of both $\triangle \mathrm{PEF}$ and $\triangle \mathrm{PEF} \%$ in identifying $\mathrm{BDR}$ was quantified as area under receiver operating characteristic (AUROC) curves. Performance of specific cut-off values of both $\triangle \mathrm{PEF}$ and $\triangle \mathrm{PEF} \%$, as well as various combinations of both together in correctly identifying subjects with BDR, was also assessed.

\section{Results}

A total of 1686 records were analysed. There were 910 men (age 15-83 years) and 776 women (age 15-80 years). BDR was documented by standard spirometric criteria in 565 (33.5\%) of these patients.

$\triangle P E F$ values showed statistically significant correlation with corresponding changes in $\mathrm{FEV}_{1}$ (Pearson's correlation coefficient 0.365, $\mathrm{p}<0.001$ ) and FVC (Pearson's correlation coefficient $0.253, \mathrm{p}<0.001) . \triangle \mathrm{PEF} \%$ values correlated marginally better with corresponding changes in $\mathrm{FEV}_{1}$ (Pearson's correlation coefficient $0.421, \mathrm{p}<0.001$ ) and FVC (Pearson's correlation coefficient $0.363, \mathrm{p}<0.001$ ) values relative to their respective baselines. However, the absolute values of the correlation coefficients were low. In addition, both $\triangle P E F$ and $\triangle P E F \%$ were poor discriminators at predicting $\mathrm{BDR}$, as AUROC values for both parameters were low $(0.673$, $95 \%$ confidence limits $0.646-0.701$, and $0.720,95 \%$ confidence limits 0.694-0.747, respectively).

Individual performance characteristics of specific $\triangle \mathrm{PEF}$ values (an increment of $20,40,60$ or $80 \mathrm{~L} /$ min over baseline) and $\triangle P E F \%$ values (an increment of $10 \%, 15 \%$ or $20 \%$ over baseline) were also studied. All these cut-off values had low or moderate sensitivity, specificity and predictive values in identifying BDR (Table 1). None of these values appeared to possess clinically useful sensitivity, while a moderately high specificity was achieved only for $\triangle \mathrm{PEF}$ exceeding $80 \mathrm{~L} / \mathrm{min}$.

\section{Discussion}

There are few data on the use of PEF to assess BDR. The present retrospective analysis is the largest study attempted on this subject. It was designed so that the results reflect an average clinician's day-to-day concerns at a primary health care level.

Table 1. Performance characteristics of various cut-offs of post-bronchodilator increment in PEF when compared to standard spirometric criteria to define post-bronchodilator responsiveness.

\begin{tabular}{|c|c|c|c|c|c|}
\hline $\begin{array}{l}\text { Change in PEF } \\
\text { over baseline }\end{array}$ & Sensitivity & Specificity & $\begin{array}{c}\text { Positive } \\
\text { predictive value }\end{array}$ & $\begin{array}{c}\text { Negative } \\
\text { predictive value }\end{array}$ & $\begin{array}{l}\text { Likelihood ratio } \\
\text { (positive) }\end{array}$ \\
\hline$>10 \%$ & 0.710 & 0.601 & 0.473 & 0.804 & 1.780 \\
\hline$>15 \%$ & 0.609 & 0.723 & 0.525 & 0.786 & 2.195 \\
\hline$>20 \%$ & 0.501 & 0.815 & 0.578 & 0.764 & 2.712 \\
\hline$>20 \mathrm{~L} / \mathrm{min}$ & 0.727 & 0.491 & 0.419 & 0.782 & 1.431 \\
\hline$>40 \mathrm{~L} / \mathrm{min}$ & 0.556 & 0.677 & 0.464 & 0.751 & 1.721 \\
\hline$>60 \mathrm{~L} / \mathrm{min}$ & 0.342 & 0.806 & 0.470 & 0.708 & 1.756 \\
\hline$>80 \mathrm{~L} / \mathrm{min}$ & 0.203 & 0.880 & 0.462 & 0.687 & 1.703 \\
\hline$>10 \%$ and $>20 \mathrm{~L} / \mathrm{min}$ & 0.690 & 0.616 & 0.476 & 0.798 & 1.799 \\
\hline$>10 \%$ and $>40 \mathrm{~L} / \mathrm{min}$ & 0.549 & 0.698 & 0.478 & 0.754 & 1.820 \\
\hline$>10 \%$ and $>60 \mathrm{~L} / \mathrm{min}$ & 0.342 & 0.806 & 0.470 & 0.708 & 1.757 \\
\hline$>10 \%$ and $>80 \mathrm{~L} / \mathrm{min}$ & 0.203 & 0.880 & 0.462 & 0.687 & 1.703 \\
\hline$>15 \%$ and $>20 \mathrm{~L} / \mathrm{min}$ & 0.603 & 0.726 & 0.526 & 0.784 & 2.204 \\
\hline$>15 \%$ and $>40 \mathrm{~L} / \mathrm{min}$ & 0.522 & 0.769 & 0.532 & 0.761 & 2.260 \\
\hline$>15 \%$ and $>60 \mathrm{~L} / \mathrm{min}$ & 0.329 & 0.829 & 0.492 & 0.710 & 1.922 \\
\hline$>15 \%$ and $>80 \mathrm{~L} / \mathrm{min}$ & 0.203 & 0.883 & 0.467 & 0.687 & 1.742 \\
\hline$>20 \%$ and $>20 \mathrm{~L} / \mathrm{min}$ & 0.501 & 0.815 & 0.578 & 0.764 & 2.712 \\
\hline$>20 \%$ and $>40 \mathrm{~L} / \mathrm{min}$ & 0.455 & 0.830 & 0.574 & 0.751 & 2.670 \\
\hline$>20 \%$ and $>60 \mathrm{~L} / \mathrm{min}$ & 0.304 & 0.856 & 0.516 & 0.709 & 2.120 \\
\hline$>20 \%$ and $>80 \mathrm{~L} / \mathrm{min}$ & 0.195 & 0.896 & 0.485 & 0.688 & 1.865 \\
\hline
\end{tabular}


Our study population was not limited to any particular disease subset, but instead constituted a large number of patients routinely referred to our Pulmonary Function Laboratory for BDR assessment. Consequently, our observations are relevant to the routine assessment of patients seen in primary care settings. Although we understand the limitations and bias of such a retrospective analysis, and we are hampered by the lack of complete clinical details for all patients, the large number of subjects studied still provides much more precise results compared to those achieved by previous investigators. ${ }^{6-9}$ In addition, we based our analysis on PEF values corrected for non-linearity of the PEF meter. Therefore the results have a wider applicability in light of the new European standards introduced in 2004.

Our results show that PEF changes after bronchodilator inhalation correlate well with corresponding $\mathrm{FEV}_{1}$ and FVC changes. However, it would appear that, irrespective of the criteria used to describe BDR based on PEF measurements, BDR defined this way is a poor discriminator in identifying true BDR based on traditional spirometry. The poor sensitivity and specificity obtained from most cut-off values studied would suggest a good deal of overlap in values between those patients who have BDR (as defined on spirometric criteria) and those who do not. Although it is difficult to compare our results with previous work due to differences in the subjects studied and the definition of BDR, the specificity and positive predictive value of PEF-based BDR in our study appear slightly lower than that reported by others.

In a study on 73 patients with asthma or COPD, the sensitivity and specificity of a $60 \mathrm{~L} / \mathrm{min}$ increase in PEF in detecting a $9 \%$ or more increase in $\mathrm{FEV}_{1}$ as a percentage of predicted value were $68 \%$ and $93 \%$, respectively, with a positive predictive value of $87 \% .{ }^{6}$ In another study on 44 patients with suspected asthma, a $>18 \%$ increase in the PEF showed a sensitivity of $85 \%$, specificity of $79 \%$, positive predictive value of $77 \%$ and negative predictive value of $86 \%$, with respect to an increase in $\mathrm{FEV}_{1}>15 \%$. $^{7} \mathrm{BDR}$ using $\mathrm{PEF}$ and $\mathrm{FEV}_{1}$ were compared using various definitions in another study on 48 patients with cough. In general, results showed high specificites, but low sensitivities and positive predictive values. ${ }^{8}$ The highest positive predictive value of $83 \%$ was found with $\triangle \mathrm{PEF} \%$ increment of $20 \%$ against an absolute $\mathrm{FEV}_{1}$ increase of $200 \mathrm{~mL}$. In another study on 176 children with asthma, $\triangle \mathrm{PEF} \%$ of $20 \%$ or $25 \%$ had a high specificity (96\% and $96 \%$, respectively), but moderate sensitivity (51\% and $53 \%$, respectively), in identifying BDR (defined as a $9 \%$ increase in $\mathrm{FEV}_{1} \%$ predicted after inhalation of $800 \mathrm{mcg}$ salbutamol). ${ }^{9}$

The sensitivity and specificity values are important in the actual clinical scenario. A test with high sensitivity is needed if PEF were to be used as a screening test to identify BDR. This is the more common situation in primary care, and clearly PEF measurements yield low sensitivities in this regard at various cut-offs. On the other hand, high specificity is preferred for a diagnostic test. Although some cut-off values do have specificity values above 0.8 , PEF still cannot be used clinically for this purpose in view of the low negative predictive values.

The timing of spirometry and PEF measurement may have introduced some bias in the results since PEF was always performed after spirometry, both for baseline and postbronchodilator assessments. Even then, post-bronchodilator PEF reading was obtained within a time-frame consistent with the nearly peak bronchodilator action of salbutamol. Although PEF is an effort-dependent test and patients may have had minor fatigue after spirometry, the same sequence was followed for all patients, and the impact (if any) on comparison between PEF and spirometry data is likely to be small in the vast majority of patients.

In conclusion, our data do not support the use of $\triangle \mathrm{PEF}$ or $\triangle \mathrm{PEF} \%$ as a surrogate for standard spirometric criteria for BDR assessment.

\section{Conflict of interest declaration}

None to declare.

\section{References}

American Thoracic Society. Lung function testing: selection of reference values and interpretative strategies. Am Rev Respir Dis 1991;144:1202-18.

2. Pellegrino $R$, Viegi $G$, Brusasco $V$, et al. Interpretative strategies for lung function tests. Eur Respir J 2005;26:948-68. doi:10.1183/ 09031936.05 .00035205

3. National Institutes of Health, National Heart Lung and Blood Institute. Update of the NHLBI/WHO Workshop Report: Global Strategy for Asthma Management and Prevention. Issued January 1995. Global Initiative for Asthma. Bethesda: National Institutes of Health, National Heart Lung and Blood Institute; Revised 2002. Document No. 02-3659, 2002.

4. British Thoracic Society, Scottish Intercollegiate Guidelines Network. British guideline on the management of asthma. Thorax 2003;58 Suppl 1:i1-94

5. Aggarwal AN, Gupta D, Jindal SK. The relationship between FEV1 and peak expiratory flow in patients with airways obstruction is poor. Chest 2006;130:1454-61. doi:10.1378/chest.130.5.1454

6. Dekker FW, Schrier AC, Sterk PJ, Dijkman JH. Validity of peak expiratory flow measurement in assessing reversibility of airflow obstruction. Thorax 1992:47:162-6. doi:10.1136/thx.47.3.162

7. Pino JM, Garcia-Rio F, Prados C, et al. Value of the peak expiratory flow in bronchodynamic tests. Allergol Immunopathol (Madr) 1996;24:54-7.

8. Thiadens HA, De Bock GH, Van Houwelingen JC, et al. Can peak expiratory flow measurements reliably identify the presence of airway obstruction and bronchodilator response as assessed by FEV1 in primary care patients presenting with a persistent cough? Thorax 1999;54:1055-60

9. Slieker MG, van der Ent CK. The diagnostic and screening capacities of peak expiratory flow measurements in the assessment of airway obstruction and bronchodilator response in children with asthma. Monaldi Arch Chest Dis 2003;59:155-9

10. American Thoracic Society. Standardization of Spirometry, 1994 Update. Am J Respir Crit Care Med 1995:152:1107-36.

11. Miller MR. Peak expiratory flow meter scale changes: implications for patients and health professionals. The Airways Journal 2004;2:80-2. 